\title{
Turismo comunitario en la zona tres del Ecuador: Un análisis de la incidencia en el desarrollo local
}

\section{Community tourism in the zone three of the Ecuador: An analysis of the incidence in the local development}

Luis Benigno Palomino Siza. ${ }^{1}$, Enrique Armando Cabanilla Vásconez. ${ }^{2}$ \& Yudel García Quintana. $^{3}$

\begin{abstract}
.
This present research focus on the analysis of the incidence on local development of the community tourism in the zone three of the Ecuador. The principal actor is the community that, based on their experiences, customs, traditions, principles and values, generate tourism projects and share with visitors in order to strengthen their good living. For this study, visits were made to the seven community tourism centers (CTC) registered in the National Tourist Cadastre, in order to interact and observe the development of tourist activities for the compilation of information through surveys and interviews that allowed determining the contribution of tourism to the communities and how it contributed in the good living of the population as long as it works articulately and in symbiosis with the final purpose to strengthen community management in tourism.
\end{abstract}

Keywords: Tourism, cultural tourism, community tourism, local development.

1 Universidad Estatal Amazónica, Centro de Posgrados, Pastaza, Ecuador, lb.palominos@uea.edu.ec

2 Universidad Central del Ecuador, Facultad de Ciencias Agrícolas, Pichincha, Ecuador, eacabanilla@uce.edu.ec

3 Universidad Estatal Amazónica, Facultad de Ciencias de la Vida, Pastaza, Ecuador, ygarcia@uea.edu.ec 


\section{Resumen.}

La presente investigación se enfoca en el análisis de la incidencia en el desarrollo local del turismo comunitario en la zona tres del Ecuador. El principal actor es la comunidad que a partir de sus experiencias, costumbres, tradiciones, principios y valores generan proyectos turísticos y comparten con los visitantes con el fin de fortalecer su buen vivir. Para este estudio, se realizaron visitas a los siete centros de turismo comunitario (CTC) registrados en el Catastro Turístico Nacional, en pro de interactuar y observar el desarrollo de las actividades turísticas para la recopilación de información a través de encuestas y entrevistas que permitieron determinar el aporte del turismo a las comunidades y como éste contribuyó en el buen vivir de la población siempre y cuando se trabaje articuladamente y en simbiosis con el propósito final de fortalecer la gestión comunitaria en el turismo.

Palabras claves: Turismo, Turismo cultural, turismo comunitario, desarrollo local.

\section{Introducción.}

Para el desarrollo de la investigación, es importante tener claro el estado del arte desde la noción del turismo en el Ecuador y cómo éste ha evolucionado paulatinamente en las comunidades de una manera responsable en torno a los derechos de los pobladores y del territorio, hasta concebirse al turismo comunitario como una herramienta de mejora de vida de la población mediante acciones de carácter económica, social y aprovechamiento de los recursos y potencialidades endógenas en pro del buen vivir que a la larga dinamizan la economía de la localidad al generar fuentes de trabajo.

\section{Turismo en Ecuador.}

Según Sancho (2008) el turismo es la industria sin chimenea que ha diversificado su oferta apegado a las nuevas tendencias de desarrollo sostenible. En tal sentido, los emprendimientos turísticos comunitarios trabajan en función del respeto por la identidad cultural y local bajo el principio de igualdad entre las organizaciones y equilibrio entre la naturaleza (Rodas, Ullauri, \& Sanmartín, 2015).

Así pues, Román \& Ciccolella (2009) manifiestan que las comunidades deben organizarse en las diversas actividades turísticas que realizan, y a la vez generar estrategias para el fortalecimiento del turismo en la región, la cual es reconocida por la Constitución de la República del Ecuador (2008) que promueve la actividad turística en un ambiente sano y ecológicamente equilibrado en pro del buen vivir de la sociedad.

En paralelo, el Plan Nacional para el Buen Vivir 2009-2013 (SENPLADES, 2009) considera al turismo como una actividad generadora de valor, producción de empleo local, producción limpia y diversificación productiva en el marco de la reconversión, a través del fomento del turismo comunitario como quinto eje, que dinamiza y diversifica la producción y los servicios, y asegura ingresos justos a las comunidades. 
Asimismo, en el Plan Nacional para el Buen Vivir 2013-2017 (SENPLADES, 2013) se reitera como un eje estratégico de acción integradora en el desarrollo territorial al turismo, así como en el Plan Nacional de Desarrollo 2017-2021: Toda una Vida (SENPLADES, 2017) donde el turismo comunitario se constituye de interés colectivo de la ciudadanía en el diseño de políticas públicas, en pro del crecimiento turístico en sus diversas modalidades en el marco de la economía popular y solidaria a lo largo del territorio nacional.

De ahí que, el turismo es parte fundamental de la dinámica y política económica de una región o país que bien gestionado promueve el desarrollo local, ya que es una actividad que fortalece el patrimonio natural y cultural de las comunidades a través del respeto mutuo entre el turista y el anfitrión.

\section{Conceptualización del turismo comunitario.}

El turismo comunitario es una organización empresarial de patrimonio comunitario (Maldonado, 2005, pág. 5); es decir, "esta clase de turismo ha emergido a los efectos negativos, sobre todo culturales y medioambientales del turismo de masas en Países en Vías de Desarrollo, permitiendo, al mismo tiempo, ser una estrategia para la organización de la propia actividad comunitaria” (Guzmán \& Sánchez, 2009, pág. 89).

Al mismo tiempo, el turismo comunitario es una forma de gestión que las comunidades realizan para el beneficio de todos los integrantes (Ruiz \& Solis, 2007), que de acuerdo con la Corporación PROCASUR (2011), son aquellas actividades turísticas solidarias de la comunidad desde una perspectiva intercultural y manejo adecuado del patrimonio; actividades, que según el Ministerio de Turismo del Ecuador (MINTUR, 2009) consiste en el ejercicio directo y exclusivo de los servicios de alojamiento, alimentos y bebidas, en los términos señalados en el artículo 5 de la Ley de Turismo por las comunidades legalmente acreditadas, organizadas y capacitadas.

En este sentido, el turismo comunitario hace hincapié en el aprovechamiento y cuidado de los recursos naturales y culturales que son de la comunidad y de los visitantes que se integran a las diversas actividades turísticas entre semana, fines de semana y vacaciones con el fin de disfrutar de su paisaje y entorno (Reyes, Ortega, \& Machado (2017).

De igual manera, el turismo comunitario es una buena oportunidad de desarrollo local, ya que integra en su dinámica características territoriales y sociales que hacen de este un modelo de gestión territorial, es decir, es un concepto en construcción que aún es discutido a nivel académico, pero que ha logrado algunos consensos básicos como: a) Reconocer el turismo comunitario como un modelo de gestión alternativo; b) Incluir a grupos étnicos, campesinos e inclusive urbanos, que ofertan diversos tipos de turismo, con variadas actividades; y, c) Ratificar el manejo integral de la comunidad en todos los procesos de la planificación, ejecución y el control del turismo en su territorio (Cabanilla, 2018). 
Sin duda, el turismo comunitario nace en un seno rural, donde prevalecen los intereses de las comunidades sobre el capital, fortaleciendo de esta manera la cadena de valor de los emprendimientos turísticos comunitarios.

\section{Historia del turismo comunitario en Ecuador.}

Según Cabanilla \& Garrido (2018) las organizaciones campesinas en el mundo empezaron a involucrarse directamente en la planificación, operatividad y gestión de las actividades turísticas que a la larga han generado desarrollo en sus comunidades a través de pequeños emprendimientos conocidos como turismo rural comunitario.

Por otro lado, en la década de los setenta en países latinoamericanos incluido Ecuador vivían tiempos de dictadura donde se impidieron el crecimiento y proceso de desarrollo que hasta ese momento se llevaban a cabo, es ahí donde se descubre el oro negro conocido como el petróleo que fue explotado a gran escala (Ayala, 2008), con ello, comienzan a darse reclamos y protestas en varios territorios locales y regionales, en donde se desarrollan indicios de acción social en el turismo que permite conllevar un trabajo colectivo, que ha sido generador por muchos años de la economía no solo del país, sino de la región y de las comunidades, datos históricos que se aprecian en la siguiente tabla.

Tabla 1. Turismo Comunitario en Ecuador.

\begin{tabular}{|c|c|}
\hline Año & Acontecimiento histórico \\
\hline 1950 & Nace el turismo comunitario en oposición a las empresas extractivas y de operación turística. \\
\hline 1968 & El Producto Turístico Galápagos se posiciona en el mercado, conocido como Ecoturismo. \\
\hline 1980 & El turismo comunitario se desarrolla de forma empírica paralelamente a la actividad turística. \\
\hline 1992 & Se crea el Ministerio de Turismo como "Ministerio de Información y Turismo". \\
\hline 1993 & $\begin{array}{l}\text { La actividad turística es adoptada por las comunidades como parte de las estrategias de la } \\
\text { Coordinadora de las Organizaciones Indígenas de la Cuenca Amazónica (COICA) y } \\
\text { Confederación de Nacionalidades Indígenas de la Amazonía Ecuatoriana (COFENIAE). }\end{array}$ \\
\hline $\begin{array}{l}\text { Finales } \\
\text { años } 90\end{array}$ & $\begin{array}{l}\text { Se desarrolla el Ecoturismo con la participación comunitaria. } \\
\text { El Consejo de Desarrollo de las Nacionalidades y Pueblos del Ecuador (CODENPE), el Proyecto } \\
\text { de Desarrollo de los Pueblos Indígenas y Negros del Ecuador (PRODEPINE) y la Organización } \\
\text { Internacional del Trabajo (OIT) proponen la necesidad y reconocimiento de la Federación } \\
\text { Plurinacional de Turismo Comunitario del Ecuador (FEPTCE). }\end{array}$ \\
\hline 2001 & $\begin{array}{l}\text { El Ministerio de Turismo (MINTUR) y la Asociación Ecuatoriana de Ecoturismo (ASEC) } \\
\text { proponen iniciativas para la legalización del Ecoturismo Comunitario. }\end{array}$ \\
\hline 2002 & $\begin{array}{l}\text { Las políticas públicas fortalecen el desarrollo del turismo comunitario a través de la Ley de } \\
\text { Turismo. }\end{array}$ \\
\hline 2007 & $\begin{array}{l}\text { Se diseña el Plan Estratégico de Desarrollo de Turismo Sostenible del Ecuador al } 2020 \\
\text { (PLANDETUR 2020), liderada por el MINTUR } \\
\text { La FEPTCE contempla dos programas centrados en el Turismo Comunitario (TC): Programa de } \\
\text { desarrollo y fortalecimiento del TC y patrimonio cultural, y el Programa de turismo de naturaleza } \\
\text { y comunitario. }\end{array}$ \\
\hline 2013 & El turismo comunitario ingresa en el Programa PLANDETUR 2020 \\
\hline
\end{tabular}
Fuente: Roux (2013).

Al respecto, a partir del posicionamiento en el mercado del producto Galápagos en los años 80 se desarrolló el turismo comunitario en el Ecuador (Ruiz \& Solis, 2007), llegando a ser un 
sector importante y de gran crecimiento económico que apoyó a más de 100 comunidades indígenas por la llegada de visitantes al continente ecuatoriano como bien lo indica la Corporación PROCASUR (2011).

Dentro de este marco, se realizaron proyectos mediante fundaciones, una de ellas, es la fundación de cooperación al desarrollo en países de América Latina, África y Asia, que abarca a todas las comunidades de pueblos y nacionalidades indígenas, y dentro de Ecuador se puso a la vista a la provincia de Imbabura en donde se beneficiaron alrededor de 36 familias comunitarias con emprendimientos turísticos y con un ingreso mensual de 246 dólares a la época (CODESPA, 2011), sin duda hasta la fecha, los emprendimientos o iniciativas comunitarias son crecientes en el turismo.

Como se puede inferir, el turismo comunitario forma parte fundamental en el desarrollo local de los distintos pueblos y nacionalidades indígenas del país por las diversas actividades turísticas que permiten la activa participación de las comunidades desde un entorno natural y cultural, que ha tenido una demanda creciente tanto de turistas nacionales como internacionales por las experiencias de autenticidad, vinculación con el ambiente y revalorización cultural vividas junto a las comunidades indígenas.

\section{Turismo como herramienta para el desarrollo.}

El término "desarrollo", se asocia al tradicional "desarrollo económico", como aquel objetivo al que los países anhelan por sobre todas las cosas, aun cuando, sus acciones imprudentes e insensatas, pasen por encima de activos tan importantes como son los recursos naturales (Ortiz \& Arévalo, 2014). En todo caso, para Monge \& Macías (2016) el término "desarrollo" ha evolucionado a la par que la civilización humana y sus diferentes contextos, expectativas, ideologías, y proyecciones; lo que significa, que el desarrollo no solo debe depender de lo económico sino al contrario debe ser direccionado a alcanzar una meta con atributos para el mejoramiento de la sociedad.

Por lo tanto, el desarrollo local toma fuerza en la década de los ochenta con el agotamiento del modelo fordista que, para esa época, no se ajustaba a las exigencias del desarrollo alcanzado por las fuerzas productivas (Morales, 2006), sino más bien abarca una política o estrategia global de desarrollo, descentralización política-administrativa, política social y económica e identidad local del territorio (Cárdenas, 2002), es decir, es un proceso de crecimiento y cambio estructural de una región, caracterizada por un sistema de producción económica, un sistema de relaciones socioculturales y un sistema político administrativo que tienen como fin aumentar la productividad y el desarrollo local (Díaz, 2018).

En ese mismo contexto, Alburquerque (2004) manifiesta que el desarrollo local es un proceso que se trabaja en el territorio con los actores e instituciones locales para apoyar las diferentes acciones, tratando de crear, reforzar y preservar actividades y empleos con los medios y recursos endógenos a fin de mejorar las condiciones del entorno local; que a criterio de Cruz, 
Ojalvo \& Velasteguí (2019) es sinónimo de crecimiento económico, que a la larga permite tomar decisiones unánimes en función de todos, lo que significa, que el desarrollo local nace con las comunidades ya existentes en territorios llenos de recuerdos y memorias, en donde lo único que buscan es el bienestar común (Arocena, 2001).

En tal sentido, la Organización Mundial del Turismo y la Organización de Estados Americanos (OMT \& OEA, 2018) mencionan que el turismo es una herramienta potencial de desarrollo y un motor de crecimiento que dinamiza la economía, pues es responsable de más del $10 \%$ del producto interno bruto mundial (PIB), aporta uno de cada diez puestos de trabajo en el mundo y mejora la calidad de vida de las personas, lo que significa, que apuntala al logro de cualquiera de los 17 Objetivos de Desarrollo Sostenible (ODS), considerando que solo está incluido directamente como meta en los Objetivos 8, 12 y 14. En fin, el turismo está firmemente posicionado en la Agenda 2030 para el Desarrollo Sostenible y de acuerdo a los reportes y experiencias contribuye directa e indirectamente a cada uno de los objetivos propuestos en el año 2015 por la Asamblea General de las Naciones Unidas que busca poner fin a la pobreza, proteger el planeta y asegurar la igualdad y prosperidad para todos (OMT, 2016).

Por otra parte, el Programa de las Naciones Unidas para el Desarrollo (PNUD, 2018) indica que es importante, en el caso del turismo medir la resiliencia que ha mostrado éste sector en los últimos años por la crisis económica mundial, y más aún en la economía local de la población como bien menciona Estrada (2015). Dentro de este marco Arias, Carpio, Herrera \& González (2016) señalan que en el Ecuador entre el año 2012 y 2013, en la región amazónica con mayor población indígena se desarrollaron diversas actividades comunitarias que incrementaron los niveles de ingreso económico.

Además, el turismo está inserto en varios países de Sudamérica como una política pública, trabajada con la participación de la ciudadanía, gobierno y la cooperación internacional (Chávez, 2008). Es decir, el buen vivir que todos anhelan, y más aún en la ruralidad, donde se prioriza las actividades que generan valor, como es el caso del turismo comunitario (Washburn, Vergara, \& Flores, 2016).

Sin duda, el turismo es una herramienta clave que juega un papel preponderante en el desarrollo de las comunidades en función del aprovechamiento de los recursos naturales y culturales que produce efectos multiplicadores en la región (Acerenza, 2013). Es así como, el desarrollo de un pueblo depende de la cohesión social y del grado de conocimiento, cultura, y tradiciones que permiten trabajar mancomunadamente en pro del buen vivir que fortalece la economía, la cultura y el ambiente bajo el principio constitucional basado en el "Sumak Kawsay" donde todos los pueblos ganan, más aún con el turismo comunitario que valoriza los derechos colectivos y de la naturaleza. 
En consecuencia, el desarrollo local abarca más que una política integral de planificación y gestión del turismo comunitario, pues es necesario lograr un cambio y un comprometimiento de las comunidades en el proceso de transformación social, ambiental y económico (Palomino, Gasca \& López, 2016), la cual evidentemente, según Díaz (2018), debe ser controlada y evaluada su gestión por la entidad competente para garantizar que los beneficios lleguen a la población. En tal sentido, el Ministerio de Turismo es el ente rector encargado del desarrollo de la actividad turística comunitaria (MINTUR, 2010).

\section{Metodologia.}

La investigación se realizó en la zona tres del Ecuador que comprende las provincias de Cotopaxi, Chimborazo, Tungurahua y Pastaza (ver figura 1), ubicada entre los 2500-2000 m.s.n.m., su territorio comprende aproximadamente de $45000 \mathrm{~km}^{2}$, con un total de 30 cantones y 139 parroquias (SENPLADES, 2017).

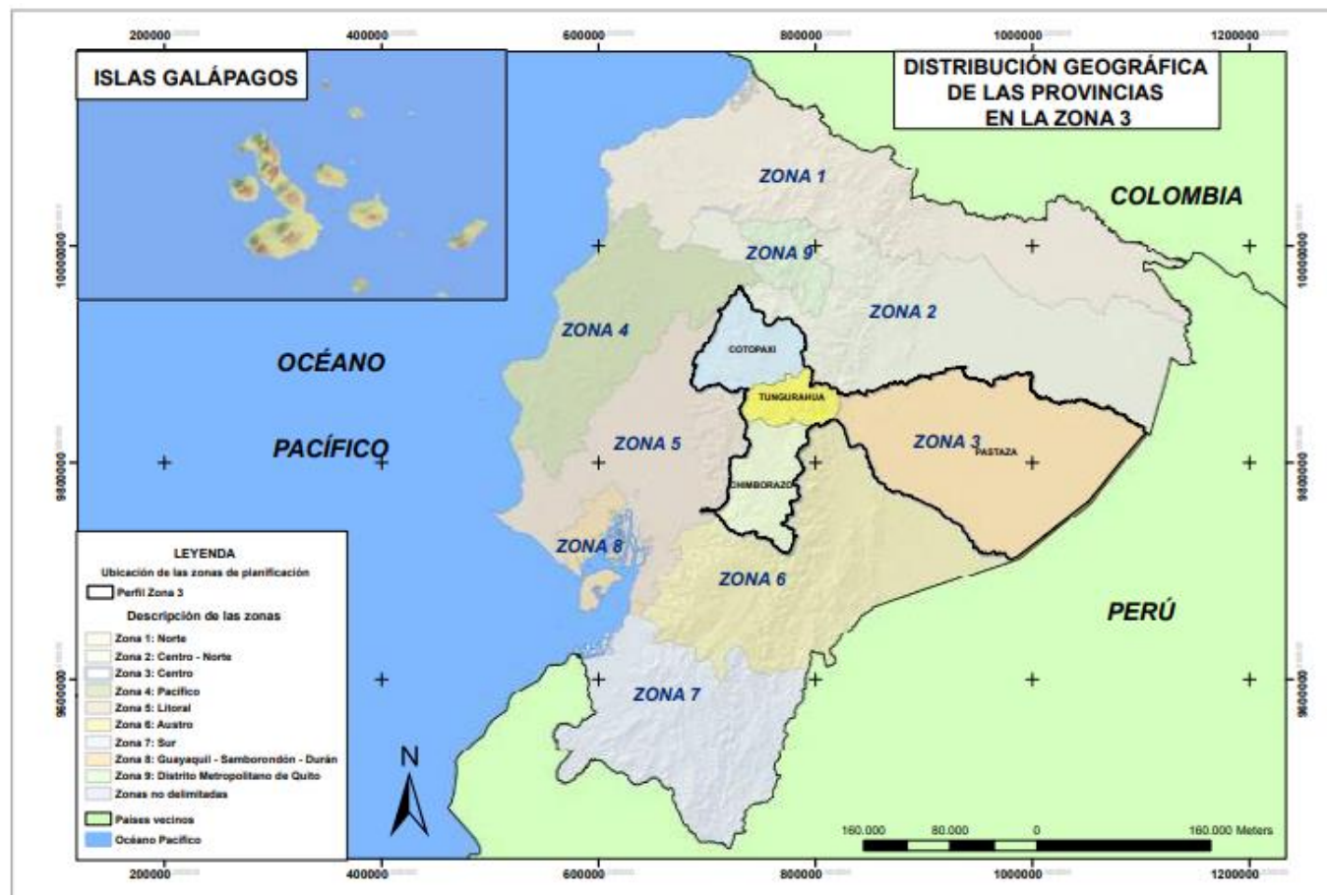

Figura 1: Provincias de la zona tres del Ecuador.

Fuente: (SENPLADES, 2017)

En este contexto, la investigación se fundamenta en el enfoque mixto que hace referencia al uso de datos numéricos así como de las características y experiencias de quienes se involucran directamente con los centros de turismo comunitario de la zona tres del Ecuador, hechos que son necesario conocer y comprender in situ a través de la investigación descriptiva y explicativa (Hernández, Fernández \& Baptista, 2014).

En tal sentido, se realizó visitas a los centros de turismo comunitario (CTC) con el fin de recopilar información a través de técnicas e instrumentos de investigación como son la 
aplicación de encuestas y entrevistas de cuestionarios estructurados, asimismo, por medio del método analítico-sintético se procedió a discernir la data, a la cual contribuyó el método inductivo-deductivo para determinar la incidencia de la actividad turística en el desarrollo local de la zona tres del Ecuador.

Para el respectivo estudio se tomó en consideración a los siete Centros de Turismo Comunitario debidamente registrados en Catastro Turístico Nacional de la zona tres del Ecuador, con un total de 988 encuestas aplicadas a través del muestreo no probabilístico por cuotas, mientras que la entrevista se dirigió a los actores y delegados de la dirección de turismo de cada provincia, como bien se indica en la siguiente tabla.

Tabla 2. Muestreo no probabilístico por cuotas.

\begin{tabular}{cccccc}
\hline & & Encuetas $=988$ & & \multicolumn{2}{c}{ Entrevistas $=4$} \\
\hline Grupo: & Grupo: & Grupo: & CTC = Zona 3 & Provincia & Dirección de \\
Empleados & Pobladores & Turistas & & & Turismo \\
20 & 196 & 217 & Lago Verde Quilotoa & Cotopaxi & 1 \\
17 & 66 & 40 & Palacio Real & & 1 \\
25 & 63 & 73 & La Moya & Chimborazo & \\
21 & 70 & 48 & Tolte-Pistishi & & 1 \\
4 & 52 & 2 & Quilla Pacari & Tungurahua & 1 \\
4 & 24 & 7 & Pondoa & Pastaza & 1 \\
10 & 24 & 5 & Sharamentsa & &
\end{tabular}

Finalizada la etapa de recolección y procesamiento estadístico de los datos se continuó con el análisis y sistematización de la información con el propósito específico de inferir principios y establecer conclusiones del objeto de estudio.

\section{Resultados y discusión.}

A través del diagnóstico realizado a los siete Centros de Turismo Comunitario de la zona tres del Ecuador legalmente registrados en el Catastro Turístico Nacional, se determinó la oferta en relación a la capacidad de la planta turística, infraestructura, calidad del servicio y trasporte, así como los precios, medios de promoción y comercialización de los productos que se ofrecen en el territorio, información que se discute en la siguiente tabla.

Tabla 3. Análisis de la oferta turística de los CTC de la zona tres del Ecuador.

\begin{tabular}{|c|c|c|c|c|c|c|c|}
\hline 记 & $\begin{array}{c}\text { Lago Verde } \\
\text { Quilotoa }\end{array}$ & Palacio Real & La Moya & Tolte-Pistishi & Quilla Pacari & Pondoa & Sharamentsa \\
\hline 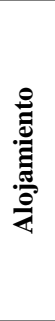 & $\begin{array}{l}\text { El Hostal } \\
\text { Princesa Toa, } \\
\text { tiene } \\
\text { habitaciones } \\
\text { individuales, } \\
\text { matrimoniales } \\
\text { y familiares } \\
\text { para } 30 \text { pax, a } \\
\$ 21 \text { y } \$ 30 \\
\text { dólares. }\end{array}$ & $\begin{array}{l}\text { Las cabañas } \\
\text { de Palacio } \\
\text { Real tienen } \\
\text { capacidad } \\
\text { para } 12 \text { pax, } \\
\text { a } \$ 15 \text { y } \$ 20 \\
\text { dólares, con } \\
\text { una sala de } \\
\text { eventos para } \\
120 \text { pax. }\end{array}$ & $\begin{array}{l}\text { La Moya oferta } \\
\text { una casa } \\
\text { familiar con } \\
\text { capacidad para } \\
20 \text { pax en sus } 3 \\
\text { habitaciones a } \\
\text { un precio de } \\
\$ 15 \text { a } \$ 20 \\
\text { dólares. }\end{array}$ & $\begin{array}{l}\text { Actualmente } \\
\text { Tolte no cuenta } \\
\text { con el servicio } \\
\text { de alojamiento. }\end{array}$ & $\begin{array}{l}\text { La comunidad } \\
\text { cuenta con } 2 \\
\text { cabañas en } \\
\text { remodelación } \\
\text { y } 6 \\
\text { habitaciones } \\
\text { con capacidad } \\
\text { para } 30 \text { pax, a } \\
\$ 15 \text { y \$20 } \\
\text { dólares. }\end{array}$ & $\begin{array}{l}\text { La } \\
\text { comunidad } \\
\text { cuenta con } 3 \\
\text { casas } \\
\text { familiares } \\
\text { para } 12 \text { pax, } \\
\text { cuyo precio } \\
\text { va de } \$ 21 \text { a } \\
\$ 30 \text { dólares. }\end{array}$ & $\begin{array}{lrr}\text { La } & \text { comunidad } \\
\text { cuenta con } & 10 \\
\text { cabañas para } & 16 \\
\text { pax, a un valor de } & \\
\$ 31 \text { dólares } & \text { en } \\
\text { medio de la } & \\
\text { Amazonía. }\end{array}$ \\
\hline
\end{tabular}




\begin{tabular}{|c|c|c|c|c|c|c|c|}
\hline 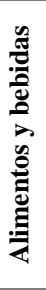 & $\begin{array}{l}\text { La comunidad } \\
\text { administra el } \\
\text { restaurante } \\
\text { KIRUTWA } \\
\text { que ofrece } \\
\text { alimentos y } \\
\text { bebidas, para } \\
50 \text { pax., a } \$ 5 \text { y } \\
\$ 10 \text { dólares. }\end{array}$ & $\begin{array}{l}\text { Se ofrece } \\
\text { comida } \\
\text { típica y } \\
\text { bebidas en el } \\
\text { restaurante } \\
\text { de la } \\
\text { comunidad a } \\
\$ 5 \text { y } \$ 10 \\
\text { dólares. }\end{array}$ & $\begin{array}{lr}\text { El restaurante } \\
\text { de } & \text { la } \\
\text { comunidad } & \\
\text { ofrece } & \text { el } \\
\text { servicio } & \text { de } \\
\text { alimentos } & \text { y } \\
\text { bebidas a un } \\
\text { precio de } \$ 5 \text { a } \\
\$ 10 \text { dólares. }\end{array}$ & $\begin{array}{l}\text { La cafetería- } \\
\text { restaurante de } \\
\text { la comunidad } \\
\text { ofrece comida } \\
\text { típica } \quad \text { y } \\
\text { bebidas a un } \\
\text { precio de } \$ 5 \text { a } \\
\$ 10 \text { dólares. }\end{array}$ & $\begin{array}{l}\text { El servicio de } \\
\text { alimentos y } \\
\text { bebidas es } \\
\text { únicamente } \\
\text { para el cliente } \\
\text { que } \\
\text { hospedan y } \\
\text { varía entre } \$ 5 \\
\text { y } \$ 10 \text { dólares. }\end{array}$ & $\begin{array}{l}\text { La } \\
\text { comunidad } \\
\text { administra el } \\
\text { restaurante y } \\
\text { ofrece } \\
\text { comida típica } \\
\text { y bebidas } \\
\text { entre \$11 y } \\
\text { \$20 dólares. }\end{array}$ & $\begin{array}{l}\text { El restaurante lo } \\
\text { administran las } \\
\text { mujeres de la } \\
\text { comunidad y tiene } \\
\text { capacidad para } 50 \\
\text { pax, a un precio de } \\
\$ 5 \text { a } \$ 10 \text { dólares. }\end{array}$ \\
\hline 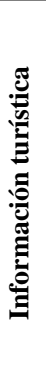 & $\begin{array}{l}\text { La comunidad } \\
\text { trabaja con la } \\
\text { operadora } \\
\text { Maquita } \\
\text { Turismo } \\
\text { Ecotrail y } \\
\text { Expedition } \\
\text { Ecuador que } \\
\text { venden la } \\
\text { laguna } \\
\text { Quilotoa. }\end{array}$ & $\begin{array}{l}\text { Se trabaja } \\
\text { con agencias } \\
\text { de viaje } \\
\text { Capac Nan, } \\
\text { Ecoviajes y } \\
\text { Latitud Cero } \\
\text { de Quito, y } \\
\text { realizan } \\
\text { guianza con } \\
\text { las mujeres } \\
\text { de la } \\
\text { comunidad. }\end{array}$ & $\begin{array}{l}\text { Se trabaja con } \\
\text { el Tren Crucero } \\
\text { que comprende } \\
\text { el recorrido a la } \\
\text { comunidad de } \\
\text { Jatari } \\
\text { Campesino y la } \\
\text { Moya, cuenta } \\
\text { con señalética, } \\
\text { senderos y } \\
\text { centro de } \\
\text { interpretación. }\end{array}$ & $\begin{array}{l}\text { La comunidad } \\
\text { cuenta con } \\
\text { señalética } \\
\text { turística, } \\
\text { senderos, } \\
\text { centro de } \\
\text { interpretación } \\
\text { y guianza, } \\
\text { desarrollada } \\
\text { por una sola } \\
\text { persona. }\end{array}$ & \begin{tabular}{lr}
\multicolumn{2}{l}{ La comunidad } \\
cuenta con \\
señalética \\
turística \\
ofrece y \\
servicio el de \\
guianza, \\
además trabaja \\
con la agencia \\
de viajes \\
Latitud Cero y \\
Terra Ecuador.
\end{tabular} & $\begin{array}{l}\text { La } \\
\text { comunidad } \\
\text { trabaja con la } \\
\text { agencia de } \\
\text { viaje Travel } \\
\text { Time y ofrece } \\
\text { el servicio de } \\
\text { guianza y } \\
\text { ascenso al } \\
\text { volcán } \\
\text { Tungurahua. }\end{array}$ & $\begin{array}{l}\text { La nacionalidad } \\
\text { Achuar cuenta con } \\
\text { una oficina de } \\
\text { información } \\
\text { turística en la } \\
\text { ciudad de Puyo, de } \\
\text { donde se oferta los } \\
\text { distintos paquetes } \\
\text { turísticos. }\end{array}$ \\
\hline 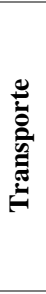 & $\begin{array}{l}\text { El transporte } \\
\text { público desde } \\
\text { la ciudad de } \\
\text { Latacunga } \\
\text { tiene un costo } \\
\text { de } \$ 2 \text { dólares. }\end{array}$ & $\begin{array}{l}\text { Para llegar a } \\
\text { la } \\
\text { comunidad } \\
\text { se toma una } \\
\text { camioneta } \\
\text { desde la } \\
\text { parroquia } \\
\text { Calpi a } \$ 2 \\
\text { dólares. }\end{array}$ & $\begin{array}{l}\text { El transporte } \\
\text { público desde la } \\
\text { terminal de } \\
\text { Riobamba a la } \\
\text { comunidad de } \\
\text { La Moya tiene } \\
\text { un valor de es } \\
\text { de } \$ 0,50 \text { ctv. }\end{array}$ & $\begin{array}{l}\text { El costo del } \\
\text { trasporte } \\
\text { público desde } \\
\text { el terminal de } \\
\text { Alausí a la } \\
\text { comunidad de } \\
\text { Tolte-Pistishi } \\
\text { es de } \$ 2 \\
\text { dólares. }\end{array}$ & $\begin{array}{l}\text { Para ingresar a } \\
\text { la comunidad } \\
\text { se debe tomar } \\
\text { una camioneta } \\
\text { desde Calpi a } \\
\text { un valor de } \\
\$ 1,50 \text { a } \$ 2 \\
\text { dólares. }\end{array}$ & $\begin{array}{l}\text { El costo de la } \\
\text { camioneta } \\
\text { para ingresar } \\
\text { a la } \\
\text { comunidad } \\
\text { desde Baños } \\
\text { está entre \$6 } \\
\text { y \$7 dólares. }\end{array}$ & $\begin{array}{l}\text { A la comunidad de } \\
\text { Montalvo se puede } \\
\text { ingresar por vía } \\
\text { aérea a un costo de } \\
\$ 300 \text { dólares, } \\
\text { también se puede } \\
\text { ingresar por vía } \\
\text { fluvial a un precio } \\
\text { de } \$ 60 \text { dólares. }\end{array}$ \\
\hline 䒿 & $\begin{array}{lr}\text { La comunidad } \\
\text { cuenta } & \text { con } \\
\text { servicios } & \text { de } \\
\text { agua, } & \text { luz, } \\
\text { teléfono, } & \\
\text { internet y el } \\
\text { servicio } \\
\begin{array}{ll}\text { recolección de } \\
\text { basura. }\end{array} \\
\end{array}$ & $\begin{array}{l}\text { La } \\
\text { comunidad } \\
\text { cuenta con } \\
\text { agua, luz, } \\
\text { teléfono, } \\
\text { internet, } \\
\text { recolección } \\
\text { de basura e } \\
\text { infocentro. }\end{array}$ & $\begin{array}{lr}\text { La comunidad } \\
\text { cuenta } & \text { con } \\
\text { agua, } & \text { luz, } \\
\text { teléfono, } & \\
\text { servicio } & \text { de } \\
\text { recolección } & \text { de } \\
\text { basura } & \text { e } \\
\text { infocentro. } & \end{array}$ & \begin{tabular}{lr}
\multicolumn{2}{l}{ La comunidad } \\
cuenta con \\
agua, luz, \\
teléfono y el \\
servicio de \\
recolección & de \\
basura & $\mathrm{e}$ \\
infocentro. &
\end{tabular} & $\begin{array}{l}\text { La comunidad } \\
\text { cuenta con } \\
\text { agua, luz, } \\
\text { teléfono y } \\
\text { recolección de } \\
\text { basura. }\end{array}$ & $\begin{array}{l}\text { La } \\
\text { comunidad } \\
\text { cuenta con } \\
\text { agua, luz, } \\
\text { teléfono, } \\
\text { internet y } \\
\text { recolección } \\
\text { de basura. }\end{array}$ & $\begin{array}{l}\text { Desde el aeropuerto } \\
\text { de la Shell se parte } \\
\text { a la comunidad de } \\
\text { Montalvo que } \\
\text { posee los servicios } \\
\text { de agua y luz. }\end{array}$ \\
\hline 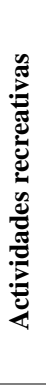 & $\begin{array}{l}\text { Se práctica } \\
\text { medina } \\
\text { ancestral, } \\
\text { senderismo en } \\
\text { la laguna de } \\
\text { Quilotoa, } \\
\text { ciclismo, } \\
\text { cabalgata, } \\
\text { kayac y se } \\
\text { desarrolla } \\
\text { eventos } \\
\text { culturales. }\end{array}$ & $\begin{array}{l}\text { Se práctica } \\
\text { senderismo, } \\
\text { cabalgatas, } \\
\text { recorridos a } \\
\text { la hacienda } \\
\text { del Pugro } \\
\text { donde se } \\
\text { hospedó } \\
\text { Simón } \\
\text { Bolívar en la } \\
\text { Gran } \\
\text { Colombia. }\end{array}$ & $\begin{array}{l}\text { En la Moya se } \\
\text { realiza } \\
\text { senderismo, } \\
\text { cabalgatas, } \\
\text { elaboración } \\
\text { venta y } \\
\text { artesanías, } \\
\text { guianza a } \\
\text { ruinas } \\
\text { templo } \\
\text { Machay. }\end{array}$ & $\begin{array}{l}\text { En Tolte se } \\
\text { desarrolla } \\
\text { senderismo, } \\
\text { ciclismo, } \\
\text { cabalgatas, } \\
\text { práctica de } \\
\text { agroturismo en } \\
\text { los huertos } \\
\text { ecológicos de } \\
\text { las familias de } \\
\text { la comunidad. }\end{array}$ & $\begin{array}{l}\text { Se práctica } \\
\text { senderismo, } \\
\text { degustación de } \\
\text { comida típica } \\
\text { y desarrollo de } \\
\text { eventos } \\
\text { culturales } \\
\text { como la danza } \\
\text { y bailes típicos } \\
\text { de la zona. }\end{array}$ & $\begin{array}{l}\text { Se desarrolla } \\
\text { senderismo, } \\
\text { visita a } \\
\text { huertos } \\
\text { orgánicos y } \\
\text { miradores } \\
\text { naturales, } \\
\text { ciclismo, } \\
\text { cabalgata y } \\
\text { ascenso al } \\
\text { volcán } \\
\text { Tungurahua. } \\
\end{array}$ & $\begin{array}{lr}\text { Se desarrolla } \\
\text { actividades como } \\
\text { trekking para } \\
\text { disfrutar de los } \\
\text { diferentes } \\
\text { atractivos turísticos } \\
\text { de la selva, práctica } \\
\text { de pesca recreativa } \\
\text { y bailes culturales } \\
\text { de la comunidad } \\
\text { Achuar. }\end{array}$ \\
\hline 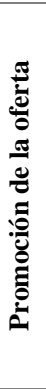 & \begin{tabular}{lr}
\multicolumn{2}{l}{ Se promociona } \\
a través de \\
agencias & de \\
viaje, páginas \\
web, redes \\
sociales & y \\
campañas & \\
televisivas & del \\
MINTUR & que \\
difunde & la \\
laguna & de \\
Quilotoa.
\end{tabular} & $\begin{array}{l}\text { Palacio Real } \\
\text { oferta sus } \\
\text { servicios por } \\
\text { medio de } \\
\text { páginas web, } \\
\text { redes } \\
\text { sociales y } \\
\text { por agencias } \\
\text { de viajes }\end{array}$ & $\begin{array}{l}\text { La Moya da a } \\
\text { conocer } \\
\text { servicios sus } \\
\text { través a } \\
\text { páginas web y } \\
\text { redes sociales. }\end{array}$ & $\begin{array}{l}\text { Se promociona } \\
\text { por paquetes } \\
\text { turísticos } \\
\text { organizados } \\
\text { por agencias de } \\
\text { viaje a la } \\
\text { estación de } \\
\text { Sibambe, redes } \\
\text { sociales y } \\
\text { campañas } \\
\text { televisivas del } \\
\text { MINTUR. }\end{array}$ & $\begin{array}{lr}\text { Oferta } & \text { sus } \\
\text { servicios } & \\
\text { turísticos } & \text { por } \\
\text { medio } & \text { de } \\
\text { agencias } & \text { de } \\
\text { viajes } & \text { y } \\
\text { páginas web. }\end{array}$ & $\begin{array}{l}\text { Se } \\
\text { promociona a } \\
\text { través de } \\
\text { agencias de } \\
\text { viajes, } \\
\text { páginas web, } \\
\text { redes sociales } \\
\text { y por el } \\
\text { MINTUR. }\end{array}$ & $\begin{array}{lr}\text { La } & \text { NAE } \\
\text { (Nacionalidad } & \\
\text { Achuar } & \text { del } \\
\text { Ecuador) es } & \text { la } \\
\text { encargada } & \text { de } \\
\text { promocionar } & \text { y } \\
\text { vender los paquetes } \\
\text { turísticos de la } \\
\text { comunidad en la } \\
\text { oficina de la ciudad } \\
\text { del Puyo. }\end{array}$ \\
\hline
\end{tabular}

Fuente: Base de datos encuesta octubre 2019-febrero 2020.

De acuerdo a la tabla anterior la mayoría de CTC presentan alojamiento con precios que van desde los \$15, \$20 y \$40 dólares, de igual manera los establecimientos son administrados 
por las personas de la comunidad, quienes trabajan en las diferentes áreas y reciben capacitaciones específicas que permiten ofrecer un servicio de calidad, es así que en Pondoa los alimentos son elaborados con productos de la zona y liderados por mujeres que han aportado significativamente al desarrollo de las comunidades.

Además, las comunidades de Lago Verde y Tolte trabajan con la operadora Maquita Turismo, La Moya es parte del proyecto Tren del Hielo I, mientras que la comunidad Sharamentsa oferta y vende paquetes turísticos. En cuanto, al servicio de transporte para el ingreso a las comunidades varía de $\$ 1$ a $\$ 5$ dólares, a excepción de Sharamentsa que específicamente para el ingreso a la Amazonía se usa avioneta a un costo de \$300 dólares. De igual manera, cada uno de los CTC cuenta con puntos de conectividad (terminales) así como el aeropuerto de la Shell para viajar a Sharamentsa, y en su mayoría presentan servicio de agua, luz, teléfono, recolección de basura y alcantarillado.

Las actividades que más sobresalen son la práctica de medicina tradicional en La Moya y Sharamentsa, así como el senderismo y deportes de aventura en Quilotoa, ascenso al volcán Tungurahua en Pondoa, cabe mencionar que todos los CTC están integrados por comunidades indígenas y son parte de las nacionalidades Panzaleo, Puruhá y Shuar, lo cual genera un gran valor agregado al turista que comparte e interactúan con la comunidad. Finalmente todos los CTC promocionan sus servicios y productos a través de cuentas oficiales en las redes sociales, páginas webs, y las diferentes agencias de viajes con quienes trabajan en la venta de paquetes turísticos, asimismo son promocionadas por el MINTUR y por el GAD correspondiente.

En paralelo se analizó la demanda para determinar el perfil general del turista que visita los diferentes CTC de la zona tres del Ecuador, siendo estas la modalidad de viaje, tiempo de estadía, promedio de gastos en alojamiento, alimentación, transporte y actividades recreativas, así como actividades de interés para los visitantes, y los medios de promoción por el cual los turistas se informan de cada uno de los centros de turismo comunitario, datos que se indican en la siguiente tabla.

Tabla 4. Demanda turística de los CTC de la zona tres del Ecuador.

\begin{tabular}{|c|c|c|c|c|c|c|c|}
\hline U & $\begin{array}{l}\text { Lago Verde } \\
\text { Quilotoa }\end{array}$ & Palacio Real & La Moya & Tolte-Pistishi & Quilla Pacari & Pondoa & Sharamentsa \\
\hline 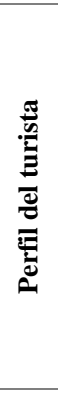 & $\begin{array}{l}\text { La edad es de } \\
19 \text { y } 32 \text { años, } \\
\text { con el } 52,5 \% \\
\text { correspondiente } \\
\text { a mujeres y la } \\
\text { diferencia a } \\
\text { hombres, de } \\
\text { nivel de } \\
\text { estudios } \\
\text { superiores, y la } \\
\text { mayoría son } \\
\text { ecuatorianos. }\end{array}$ & $\begin{array}{l}\text { Los turistas } \\
\text { tienen de } 51 \\
\text { a } 60 \text { años de } \\
\text { edad, el } 45 \% \\
\text { es femenino } \\
\text { y la } \\
\text { diferencia es } \\
\text { masculino, y } \\
\text { el } 80 \% \text { son } \\
\text { ecuatorianos. }\end{array}$ & $\begin{array}{l}\text { La edad de } \\
\text { los turistas es } \\
\text { de } 26 \text { a } 32 \\
\text { años, el } \\
53,4 \% \\
\text { corresponde } \\
\text { a mujeres y } \\
\text { el } 46,6 \% \text { a } \\
\text { hombres, } \\
\text { donde el } \\
98.6 \% \text { son } \\
\text { ecuatorianos. }\end{array}$ & $\begin{array}{l}\text { La edad de los } \\
\text { visitantes es de } \\
51 \text { a } 60 \text { años, el } \\
58,3 \% \\
\text { corresponde } \\
\text { mujeres y el } \\
41,7 \% \text { el } \\
\text { hombres, en } \text { a su } \\
\text { mayoría } \\
\text { provienen de } \\
\begin{array}{ll}\text { Norteamérica } \\
(66,7 \%) \text {. }\end{array} \\
\end{array}$ & $\begin{array}{l}\text { La edad de los } \\
\text { turistas es de } \\
33 \text { a } 39 \text { años, } \\
\text { en un } 80 \% \text { son } \\
\text { ecuatorianos y } \\
\text { poseen } \\
\text { educación } \\
\text { superior. }\end{array}$ & $\begin{array}{l}\text { La edad de los } \\
\text { turistas va de } \\
40 \text { a } 50 \text { años, } \\
\text { en su mayoría } \\
\text { son mujeres } \\
(71,42 \%) \text {, y de } \\
\text { nacionalidad } \\
\text { ecuatoriana. }\end{array}$ & $\begin{array}{l}\text { La mayoría de los } \\
\text { turistas que } \\
\text { ingresan son de } \\
\text { nacionalidad } \\
\text { Alemana } \\
\text { Japonesa, de una } \\
\text { edad de } 19 \text { a } 32 \\
\text { años con un } 82 \% \\
\text { correspondiente a } \\
\text { mujeres. }\end{array}$ \\
\hline
\end{tabular}




\begin{tabular}{|c|c|c|c|c|c|c|c|}
\hline 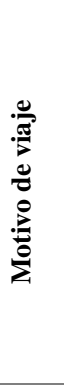 & $\begin{array}{l}\text { El } 79,2 \% \text { de } \\
\text { turistas visitan } \\
\text { el CTC por la } \\
\text { laguna de } \\
\text { Quilotoa, y el } \\
\text { restante por las } \\
\text { costumbres y } \\
\text { tradiciones de } \\
\text { la población, se } \\
\text { quedan de } 4 \text { a } 6 \\
\text { horas y hasta } \\
\text { por dos días. }\end{array}$ & 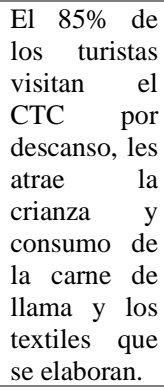 & $\begin{array}{l}\text { El } 85 \% \text { de } \\
\text { los turistas } \\
\text { visitan el } \\
\text { lugar por } \\
\text { descanso y } \\
\text { por convivir } \\
\text { con la } \\
\text { comunidad y } \\
\text { aprender de } \\
\text { sus } \\
\text { costumbres y } \\
\text { tradiciones. }\end{array}$ & $\begin{array}{l}\text { El } 54,2 \% \text { de los } \\
\text { turistas ingresan } \\
\text { por descanso, el } \\
45,8 \% \text { por } \\
\text { aventura, y en su } \\
\text { mayoría } \\
\text { practican } \\
\text { senderismo el al } \\
\text { mirador de la } \\
\text { montaña Nariz } \\
\text { del Diablo. }\end{array}$ & $\begin{array}{l}\text { Los visitantes } \\
\text { en su mayoría } \\
\text { ingresan por } \\
\text { descanso, } \\
\text { convivencia y } \\
\text { por conocer de } \\
\text { las costumbres } \\
\text { y tradiciones } \\
\text { de la } \\
\text { comunidad, y } \\
\text { se quedan de } 1 \\
\text { a } 3 \text { horas. }\end{array}$ & $\begin{array}{lr}\text { El } 71,4 \% & \text { de } \\
\text { los turistas } \\
\text { visitan la } \\
\text { comunidad por } \\
\text { descansar } \\
\text { recorrer } y \\
\text { atractivos } \\
\text { turísticos y el } \\
28,6 \% \text { por } \\
\text { aventura con } \\
\text { una estadía de } \\
\text { dos días. }\end{array}$ & $\begin{array}{l}\text { Los turistas } \\
\text { visitan el CTC por } \\
\text { descanso } \\
\text { convivencia con la } \\
\text { comunidad } \\
\text { Achuar, } \\
\text { promedio } \\
\text { mayoría se quedan } \\
4 \text { días. }\end{array}$ \\
\hline 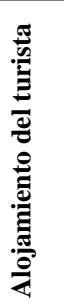 & $\begin{array}{l}\text { El } 74,6 \% \text { de los } \\
\text { visitantes } \\
\text { prefiere } \\
\text { cabañas, el } \\
12,4 \% \text { casas } \\
\text { familiares, el } \\
12 \% \text { camping y } \\
\text { el } 1 \% \text { se inclina } \\
\text { por un refugio. }\end{array}$ & $\begin{array}{l}\text { Los turistas } \\
\text { en su } \\
\text { totalidad } \\
\text { manifiestan } \\
\text { hospedarse } \\
\text { en cabañas } \\
\text { atendidos } \\
\text { por la } \\
\text { comunidad. }\end{array}$ & $\begin{array}{l}\text { El 86,3\% de } \\
\text { los turistas } \\
\text { prefieren } \\
\text { descansar en } \\
\text { cabañas, } \\
\text { mientras que } \\
\text { la diferencia } \\
\text { en casas } \\
\text { familiares. }\end{array}$ & $\begin{array}{l}\text { Actualmente el } \\
\text { CTC no cuenta } \\
\text { con hospedaje, } \\
\text { pero los turistas } \\
\text { en su totalidad } \\
\text { manifiestan su } \\
\text { deseo por las } \\
\text { cabañas. }\end{array}$ & $\begin{array}{lr}\text { Todos } & \text { los } \\
\text { turistas } & \\
\text { expresan } & \text { su } \\
\text { deseo } & \text { por } \\
\text { hospedarse } & \text { en } \\
\text { cabañas. } & \end{array}$ & $\begin{array}{lr}\text { Todos } & \text { los } \\
\text { turistas } & \\
\text { expresan } & \text { su } \\
\text { deseo } & \text { por } \\
\text { hospedarse } & \text { en } \\
\text { cabañas. } & \end{array}$ & $\begin{array}{l}\text { Todos los turistas } \\
\text { expresan su deseo } \\
\text { por hospedarse en } \\
\text { cabañas. }\end{array}$ \\
\hline 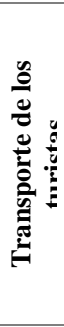 & $\begin{array}{l}\text { El 48,3\% llegan } \\
\text { en vehículo } \\
\text { propio, el } \\
32,2 \% \\
\text { transporte } \\
\text { público, el } 18 \% \\
\text { en transporte } \\
\text { turístico y el } \\
1,5 \% \text { utilizan } \\
\text { camionetas. }\end{array}$ & $\begin{array}{l}\text { Para llegar al } \\
\text { CTC, el } 60 \% \\
\text { utiliza } \\
\text { transporte } \\
\text { turístico, y el } \\
40 \% \\
\text { transporte } \\
\text { propio por } \\
\text { comodidad y } \\
\text { seguridad. }\end{array}$ & $\begin{array}{l}\text { El 93,2\% de } \\
\text { los turistas } \\
\text { llega al CTC } \\
\text { en transporte } \\
\text { turístico y el } \\
6,8 \% \text { utiliza } \\
\text { transporte } \\
\text { inter- } \\
\text { cantonal. }\end{array}$ & $\begin{array}{l}\text { Los turistas } \\
\text { llegan al CTC en } \\
\text { un 79,2\% en } \\
\text { transporte } \\
\text { turístico y el } \\
20,8 \% \text { con } \\
\text { vehículo propio. }\end{array}$ & $\begin{array}{l}\text { El 90\% de los } \\
\text { visitantes } \\
\text { llegan al lugar } \\
\text { con vehículo } \\
\text { propio, y el } \\
\text { restante } \\
\text { través a } \\
\text { trasporte } \\
\text { turístico. }\end{array}$ & $\begin{array}{l}\text { El } 85,7 \% \text { llega } \\
\text { al CTC con } \\
\text { vehículo } \\
\text { propio y el } \\
14,3 \% \text { hacen } \\
\text { uso de una } \\
\text { camioneta } \\
\text { desde Baños. }\end{array}$ & $\begin{array}{l}\text { El único medio } \\
\text { seguro para llegar } \\
\text { al CTC es por vía } \\
\text { aérea, con } \\
\text { respecto a la vía } \\
\text { fluvial } \\
\text { peligroso y dura } 4 \\
\text { horas } \\
\text { aproximadamente. }\end{array}$ \\
\hline 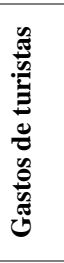 & $\begin{array}{lr}\text { El turista } & \text { gasta } \\
\text { entre } \$ 25 \text { y } & \$ 30 \\
\text { dólares } & \text { en } \\
\text { diversas } & \\
\text { actividades } & \\
\text { alrededor de } & \text { la } \\
\text { laguna } & \text { de } \\
\text { Quilotoa. }\end{array}$ & $\begin{array}{l}\text { El } 90 \% \text { de } \\
\text { los visitantes } \\
\text { gasta entre } \\
\$ 31 \text { y } \$ 40, \\
\text { mientras que } \\
\text { el } 10 \% \text { gasta } \\
\text { más de } \$ 41 \\
\text { dólares. }\end{array}$ & $\begin{array}{l}\text { El } 45,2 \% \\
\text { gastan de } \\
\$ 31 \text { a } \$ 40, \text { el } \\
43,8 \% \text { de } \\
\$ 25 \text { a } \$ 30 \text { y } \\
\text { el } 11 \% \text { más } \\
\text { de } \$ 41 \\
\text { dólares. }\end{array}$ & $\begin{array}{l}\text { El gasto es de } \\
\$ 31 \text { a } \$ 40 \text { que } \\
\text { corresponde al } \\
31,3 \% \text { mientras } \\
\text { que el } 6,3 \% \text { de } \\
\$ 25 \text { a } \$ 30 \text { y el } \\
62,4 \% \text { más de } \\
\$ 41 \text { dólares. }\end{array}$ & $\begin{array}{l}\text { El gasto de los } \\
\text { turistas es de } \\
\$ 25 \text { a } \$ 30 \\
\text { dólares en } \\
\text { alojamiento y } \\
\text { alimentación. }\end{array}$ & $\begin{array}{l}\text { En promedio el } \\
\text { gasto de los } \\
\text { turistas es } \$ 41 \\
\text { dólares en } \\
\text { alojamiento y } \\
\text { restauración. }\end{array}$ & $\begin{array}{l}\text { El turista gasta en } \\
\text { promedio } \$ 250 \\
\text { dólares por las } \\
\text { condiciones } \\
\text { propias de la } \\
\text { amazonia. }\end{array}$ \\
\hline 苞 & $\begin{array}{l}\text { En su mayoría } \\
\text { que representa } \\
\text { el } 47,5 \% \text { de los } \\
\text { turistas } \\
\text { practican } \\
\text { senderismo. }\end{array}$ & $\begin{array}{l}\text { El 40,8\% de } \\
\text { los turísticas } \\
\text { practican } \\
\text { senderismo y } \\
\text { degustan de } \\
\text { la } \\
\text { gastronomía. }\end{array}$ & $\begin{array}{l}\text { El } 31,9 \% \text { de } \\
\text { los turistas } \\
\text { visitan los } \\
\text { atractivos y } \\
\text { degustan de } \\
\text { la } \\
\text { gastronomía. }\end{array}$ & $\begin{array}{l}\text { En su mayoría } \\
\text { que representa el } \\
48,5 \% \text { de los } \\
\text { turistas visitan } \\
\text { los atractivos } \\
\text { como el mirador } \\
\text { Nariz del Diablo. }\end{array}$ & $\begin{array}{l}\text { El } 44,4 \% \text { de } \\
\text { los turistas } \\
\text { realizan } \\
\text { senderismo, el } \\
44,5 \% \text { visitan } \\
\text { los atractivos } \\
\text { turísticos y el } \\
11,1 \% \text { se } \\
\text { interesa por la } \\
\text { comida típica. }\end{array}$ & $\begin{array}{l}\text { El 41,2\% } \\
\text { realizan } \\
\text { senderismo, el } \\
52,9 \% \\
\text { practican } \\
\text { agroturismo, y } \\
\text { el 5,9\% } \\
\text { ascienden al } \\
\text { volcán } \\
\text { Tungurahua. }\end{array}$ & $\begin{array}{l}\text { El } 22 \% \text { de turistas } \\
\text { practican } \\
\text { senderismo, el } \\
23 \% \text { degustan la } \\
\text { comida típica, el } \\
23 \% \text { avistamiento } \\
\text { de flora y fauna y } \\
\text { el } 32 \% \text { practican } \\
\text { el turismo } \\
\text { vivencial. }\end{array}$ \\
\hline & $\begin{array}{l}\text { Los visitantes } \\
\text { indican que se } \\
\text { informaron por } \\
\text { redes sociales, } \\
\text { amigos, } \\
\text { agencias de } \\
\text { viaje y en ferias } \\
\text { de turismo. }\end{array}$ & $\begin{array}{l}\text { Los turistas } \\
\text { en general } \\
\text { llegaron al } \\
\text { lugar por la } \\
\text { información } \\
\text { puesta en las } \\
\text { redes } \\
\text { sociales. }\end{array}$ & $\begin{array}{l}\text { Los } \\
\text { visitantes } \\
\text { indican que } \\
\text { se informan } \\
\text { por redes } \\
\text { sociales para } \\
\text { llegar a la } \\
\text { comunidad. }\end{array}$ & $\begin{array}{l}\text { A más de las } \\
\text { recomendaciones } \\
\text { de los amigos los } \\
\text { turistas } \\
\text { mencionan } \\
\text { haberse } \\
\text { informado por } \\
\text { redes sociales. }\end{array}$ & $\begin{array}{l}\text { La mayoría de } \\
\text { los visitantes } \\
\text { se informan } \\
\text { por redes } \\
\text { sociales y por } \\
\text { recomendación } \\
\text { de los amigos. }\end{array}$ & $\begin{array}{l}\text { Los visitantes } \\
\text { se informan del } \\
\text { CTC por redes } \\
\text { sociales, } \\
\text { recomendación } \\
\text { de sus amigos } \\
\text { y por agencias } \\
\text { de viaje. }\end{array}$ & $\begin{array}{lr}\text { Los turistas } \\
\text { acceden a la } \\
\text { información del } \\
\text { CTC por la página } \\
\text { web de Pastaza } \\
\text { travel, así como de } \\
\text { la respectiva } \\
\text { agencia de viaje. }\end{array}$ \\
\hline
\end{tabular}

Fuente: Base de datos encuesta octubre 2019-febrero 2020.

En relación a la tabla anterior, la edad de los turistas que llegan a los CTC son de 19 a 50 años, donde Tolte, Palacio Real, Quilla Pacari y Sharamentsa reciben un $90 \%$ de turistas alemanes, norteamericanos y canadienses, y el $10 \%$ son turistas nacionales, mientras que en Quilotoa, La Moya y Pondoa en su mayoría son visitantes nacionales. La permanencia de los 
turistas en las comunidades varia de 4 a 6 horas, no obstante en Sharamentsa, Pondoa y Quilla Pacari permanecen más de un día, es así que los turistas prefieren hospedarse en cabañas.

En los CTC de La Moya, Tolte, Quilotoa, Quilla Pacari, Pondoa y Palacio Real, la mayoría viajan en transporte turístico consolidado en el respectivo paquete, mientras que, en Sharamentsa ingresan por medio de una avioneta, lo cual eleva los costos, no obstante el gasto de quienes visitan los distintos CTC está entre los \$25 y \$40 dólares que se destinan en forma general para alimentación, práctica de senderismo, cabalgatas y deportes de aventura.

En general el turista que visita cada uno de los CTC de la zona tres del Ecuador tiene un gran interés por la naturaleza y las actividades derivadas en ella al aire libre, como es el avistamiento de flora y fauna, la práctica de agroturismo y un turismo más vivencial que contribuye al desarrollo de las comunidades, lo cual se ejecuta a través del turismo comunitario que busca durante la estadía del turista satisfacer sus necesidades y cubrir con todas sus expectativas de viaje, que son publicitadas por medio de redes sociales, agencias de viaje y por los propios turistas tanto nacionales como extranjeros que actúan como medios de difusión por el servicio de calidad prestado por la comunidad.

En efecto, el turismo comunitario es un motor de desarrollo para las comunidades siempre y cuando a través de éste se genere plazas de empleo, venta de artesanías, eventos culturales e innovación de productos y servicios de la mano de la conservación ambiental y con el trabajo colaborativo de todos con el fin de dinamizar la economía local y buen vivir de las comunidades. Es así, que en la siguiente tabla se analiza la estructura demográfica y el analfabetismo con respecto a los siete centros de turismo comunitario de la zona tres del Ecuador.

Tabla 5. Estructura demográfica y analfabetismo de los CTC de la zona tres del Ecuador.

\begin{tabular}{|c|c|c|c|c|c|c|c|}
\hline ย & $\begin{array}{c}\text { Lago Verde } \\
\text { Quilotoa }\end{array}$ & $\begin{array}{c}\text { Palacio } \\
\text { Real }\end{array}$ & La Moya & Tolte-Pistishi & Quilla Pacari & Pondoa & Sharamentsa \\
\hline 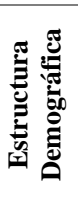 & $\begin{array}{l}\text { La edad es de } \\
33-39 \text { años, } \\
\text { donde el } \\
58,7 \% \text { tiene } \\
\text { estudios } \\
\text { primarios. }\end{array}$ & $\begin{array}{l}\text { La edad es } \\
\text { de } 33-39 \\
\text { años, donde } \\
\text { el } 56,1 \% \text { ha } \\
\text { terminado la } \\
\text { primaria. }\end{array}$ & $\begin{array}{l}\text { La edad es } \\
33-39 \quad \text { de } \\
\text { donde } \\
63,5 \% \\
\text { terminado } \\
\text { primaria. }\end{array}$ & $\begin{array}{l}\text { La edad es de } \\
40-50 \text { años, } \\
\text { donde el } 70 \% \\
\text { cuenta solo con } \\
\text { educación } \\
\text { primaria. }\end{array}$ & $\begin{array}{l}\text { La edad es de } \\
33 \text { a } 39 \text { años, } \\
\text { donde } \\
63,5 \% \\
\text { terminado } \\
\text { primaria. }\end{array}$ & $\begin{array}{l}\text { La edad es de } \\
40-50 \text { años, } \\
\text { donde el } 78 \% \\
\text { ha terminado } \\
\text { la primaria. }\end{array}$ & $\begin{array}{l}\text { La edad es de } 51- \\
60 \text { años, donde } \\
\text { apenas el } 14 \% \\
\text { saben leer y } \\
\text { escribir. }\end{array}$ \\
\hline 总 & $\begin{array}{l}\text { La mayor } \\
\text { parte de la } \\
\text { población se } \\
\text { ha educado, } \\
\text { mientras que } \\
\text { el } 8,2 \% \text { no ha } \\
\text { estudiado. }\end{array}$ & $\begin{array}{l}\text { La mayor } \\
\text { parte de la } \\
\text { población se } \\
\text { ha educado, } \\
\text { y el } 9,1 \% \text { no } \\
\text { ha } \\
\text { estudiado. }\end{array}$ & $\begin{array}{l}\text { La comunidad } \\
\text { en su mayoría } \\
\text { se ha educado, } \\
\text { mientras que el } \\
20,6 \% \text { no ha } \\
\text { estudiado. }\end{array}$ & $\begin{array}{l}\text { El nivel de } \\
\text { educación de la } \\
\text { comunidad es } \\
\text { alta, ya que el } \\
5,7 \% \text { de la } \\
\text { población no ha } \\
\text { estudiado. }\end{array}$ & $\begin{array}{l}\text { El nivel de } \\
\text { educación de } \\
\text { la comunidad } \\
\text { es alta, ya que } \\
\text { el } 7.7 \% \text { no ha } \\
\text { estudiado. }\end{array}$ & $\begin{array}{l}\text { Toda la } \\
\text { comunidad } \\
\text { manifiesta } \\
\text { haber } \\
\text { accedido a la } \\
\text { educación. }\end{array}$ & $\begin{array}{l}\text { Por no contar con } \\
\text { centros } \\
\text { educación } \\
\text { cercanos a la } \\
\text { comunidad, el } \\
86 \% \text { no ha podido } \\
\text { educarse. }\end{array}$ \\
\hline
\end{tabular}

Fuente: Base de datos encuesta octubre 2019-febrero 2020.

Las comunidades presentan más mujeres que hombres en los diferentes CTC de la zona tres del Ecuador, sin embargo, en Lago Verde-Quilotoa, Sharamentsa y Pondoa el número es equilibrado, con una edad de la población entre 33-39 años y 40-60 años que corresponden a 
personas con saberes ancestrales, además las comunidades superan el 58\% de acceso a la educación primaria a excepción de Sharamentsa que apenas alcanza el 14\%, por lo que gran parte de las comunidades se dedican a la agricultura, no obstante también trabajan en el turismo, es así, que en Tolte y Quilotoa se realizan artesanías y son dueños de sus propios negocios.

A pesar de que la educación es limitada, gran parte de las comunidades se han educado. En este sentido, en promedio el 10,26\% de las personas no han estudiado, e incluso en Sharamentsa alcanza el $86 \%$ de analfabetismo por lo difícil que es el trasladarse hasta un centro de educación cercano.

Por otra parte, en la siguiente tabla se analiza la estructura económica de los CTC de la zona tres del Ecuador concerniente a las principales fuentes de ingreso, tipos de emprendimiento y acceso tecnológico que permite el equilibrio y desarrollo local de cada una de las comunidades.

Tabla 6. Factor económico, empresarial y tecnológico de los CTC de la zona tres del Ecuador.

\begin{tabular}{|c|c|c|c|c|c|c|c|}
\hline U & $\begin{array}{c}\text { Lago Verde } \\
\text { Quilotoa }\end{array}$ & Palacio Real & La Moya & $\begin{array}{c}\text { Tolte- } \\
\text { Pistishi }\end{array}$ & Quilla Pacari & Pondoa & Sharamentsa \\
\hline 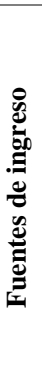 & $\begin{array}{l}\text { El } 10,3 \% \text { son } \\
\text { estudiantes y } \\
\text { amas de casa, } \\
\text { el } 37 \% \text { se } \\
\text { dedica al } \\
\text { turismo, el } \\
48,5 \% \text { a la } \\
\text { agricultura y } \\
\text { ganadería y el } \\
\text { restante a las } \\
\text { labores } \\
\text { artesanales }\end{array}$ & \begin{tabular}{lr}
\multicolumn{3}{l}{ La agricultura } \\
alcanza & el \\
$44,8 \%$, & la \\
ganadería & y \\
crianza & de \\
llamas & el \\
$17,2 \%$, & el \\
turismo el \\
$21,8 \%$ y la \\
elaboración \\
de artesanías \\
el 16,2\%.
\end{tabular} & $\begin{array}{l}\text { Los ingresos } \\
\text { provienen de } \\
\text { la agricultura } \\
(42,0 \%), \\
\text { ganadería } \\
(32,8 \%) \text {, } \\
\text { turismo } \\
(24,4 \%) \text { y de } \\
\text { la elaboración } \\
\text { de artesanías } \\
(0,8 \%) \text {. }\end{array}$ & $\begin{array}{l}\text { Los ingresos } \\
\text { provienen de } \\
\text { la agricultura } \\
\text {-agroturismo } \\
(38,6 \%), \\
\text { artesanías } \\
(28,6 \%) \text {, } \\
\text { construcción } \\
(17,1 \%) \text { y el } \\
\text { restante del } \\
\text { comercio en } \\
\text { general. }\end{array}$ & $\begin{array}{lr}\text { La población } \\
\text { percibe } \\
\text { ingresos con un } \\
71,7 \% \text { de la } \\
\text { agricultura, el } \\
26,4 \% \text { trabajan } \\
\text { en la ganadería y } \\
\text { el } 1,9 \% & \text { se } \\
\text { dedican a la } \\
\text { producción } \\
\text { artesanal } \\
\text { textil. }\end{array}$ & 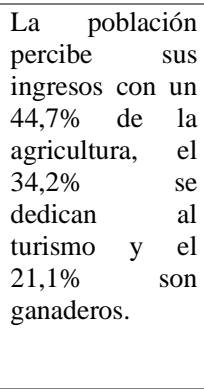 & $\begin{array}{l}\text { El } 85 \% \text { de la } \\
\text { población } \\
\text { percibe sus } \\
\text { ingresos a través } \\
\text { de la agricultura, } \\
\text { pesca, caza y la } \\
\text { práctica de } \\
\text { turismo, y el } \\
15 \% \text { se dedica a } \\
\text { elaborar } \\
\text { artesanías. }\end{array}$ \\
\hline & $\begin{array}{l}\text { El } 52,1 \% \\
\text { desarrolla } \\
\text { turismo, el } \\
27,4 \% \text { genera } \\
\text { artesanías } \quad \mathrm{y} \\
\text { textiles y } \text { el } \\
20,5 \% \text { se } \\
\text { dedica a la } \\
\text { producción } \\
\text { venta } \\
\text { lácteos. }\end{array}$ & $\begin{array}{lr}\text { El } & 32,4 \% \\
\text { trabaja } & \text { en } \\
\text { turismo, el } \\
34,6 \% \text { genera } \\
\text { artesanías } \text { y } \\
\text { textiles, y el } \\
33 \% \text { se dedica } \\
\text { a ra la } \\
\text { producción y } \\
\text { venta de } \\
\text { lácteos. }\end{array}$ & $\begin{array}{lr}\text { El } & 25,7 \% \\
\text { trabaja } & \text { en } \\
\text { turismo, el } \\
24,8 \% \text { genera } \\
\text { artesanías } \quad \mathrm{y} \\
\text { textiles, y el } \\
49,5 \% \text { se } \\
\text { dedica a la } \\
\text { producción y } \\
\text { venta } \\
\text { lácteos. }\end{array}$ & $\begin{array}{l}\text { La población } \\
\text { trabaja en un } \\
55,5 \% \text { en } \\
\text { turismo por } \\
\text { el mirador } \\
\text { Nariz del } \\
\text { Diablo, y el } \\
44,5 \% \\
\text { desarrolla } \\
\text { artesanías y } \\
\text { textiles. }\end{array}$ & $\begin{array}{l}\text { El } 82,4 \% \text { de la } \\
\text { población } \\
\text { trabaja en la } \\
\text { producción } \\
\text { venta de lácteos, } \\
\text { el } 11,8 \% \\
\text { turismo y en } \\
\begin{array}{ll}5,8 \% \\
\text { artesanías } \\
\text { textiles. }\end{array}\end{array}$ & $\begin{array}{l}\begin{array}{l}\text { Debido a las } \\
\text { condiciones } \\
\text { naturales }\end{array} \\
53,1 \% \text { trabaja en } \\
\text { turismo y el } \\
46,9 \% \text { en la } \\
\text { producción y } \\
\text { venta de lácteos. }\end{array}$ & $\begin{array}{l}\text { La comunidad } \\
\text { conjuga las } \\
\text { diversas } \\
\text { actividades con } \\
\text { el turismo. }\end{array}$ \\
\hline שֶ & $\begin{array}{l}\text { El } 52,6 \% \text { de } \\
\text { la población } \\
\text { tiene acceso a } \\
\text { la tecnología } \\
\text { y el } 47,4 \% \text { no. }\end{array}$ & $\begin{array}{l}\text { El } 80,3 \% \text { de la } \\
\text { población } \\
\text { tiene acceso a } \\
\text { la tecnología, } \\
\text { y el } 19,7 \% \text { no. }\end{array}$ & $\begin{array}{l}\text { El } 90,5 \% \text { no } \\
\text { tiene acceso a } \\
\text { la tecnología } \\
\text { y el } 9.5 \% \text { si } \\
\text { tiene acceso a } \\
\text { la misma. }\end{array}$ & $\begin{array}{l}\text { El } 54,3 \% \text { de } \\
\text { la población } \\
\text { no tiene } \\
\text { acceso a la } \\
\text { tecnología y } \\
\text { el 45,7\% sí. }\end{array}$ & $\begin{array}{l}\text { La mayoría de la } \\
\text { comunidad no } \\
\text { tiene acceso a la } \\
\text { tecnología } \\
(56,5 \%) \text { y el } \\
43,5 \% \text { sí. }\end{array}$ & $\begin{array}{l}\text { La mayoría no } \\
\text { tiene acceso a la } \\
\text { tecnología } \\
(57,7 \%) \text {, } \\
\text { mientras que el } \\
42,3 \% \text { sí. }\end{array}$ & $\begin{array}{lr}\text { Debido al difícil } \\
\text { acceso, } \\
\text { amazonía } \\
\text { cuenta no } \\
\text { condiciones } \\
\text { tecnológicas. }\end{array}$ \\
\hline
\end{tabular}

Fuente: Base de datos encuesta octubre 2019-febrero 2020.

Como se aprecia en la tabla anterior, alrededor del $75 \%$ de la población cuentan con un trabajo fijo, del cual el $40.1 \%$ en promedio perciben sus ingresos por la actividad turística, mientras que en Quilla Pacari recién se está proyectando el turismo, siendo la agricultura el ingreso principal con el $71,7 \%$. No obstante, la agricultura representa la primera fuente de 
ingresos de las comunidades con el 50,9\%, seguido del turismo y la producción artesanal y textil.

En esta línea de ideas, los emprendimientos turísticos representan en promedio el 47\%, seguido de la producción y venta de lácteos con el $46 \%$, y de los textiles y artesanías con el $27 \%$, es decir los emprendimientos turísticos dinamizan la economía y el desarrollo local de las comunidades, a través de diversas actividades que los pobladores realizan en pro del buen vivir. En este contexto, en promedio el $60,8 \%$ de la población no tiene acceso a la tecnología y menos aún dispone de internet.

Desde la perspectiva de la comunidad, el turismo comunitario tiene gran acogida y en algunos casos es parte del desarrollo y buen vivir de la población en el territorio como se indica en la siguiente tabla.

Tabla 7. Perspectiva de la comunidad de cada CTC de la zona tres del Ecuador.

\begin{tabular}{|c|c|c|c|c|c|c|c|}
\hline Centro de Turismo Comunitario & 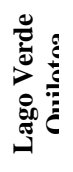 & 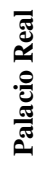 & 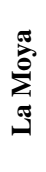 & 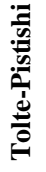 & 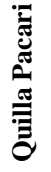 & 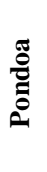 & 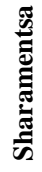 \\
\hline $\begin{array}{l}\text { La comunidad apoya al CTC, ya que, ha generado desarrollo y fuentes de empleo en los } \\
\text { últimos años, y con ello la población ha emprendido en hospedaje, alimentación, entre } \\
\text { otros. }\end{array}$ & $\mathrm{X}$ & & & & & & \\
\hline $\begin{array}{l}\text { La población apoya al CTC, ya que, ha ayudado a reducir la pobreza y migración a través } \\
\text { de la llegada de turistas a la comunidad que disfrutan de las danzas, artesanías y } \\
\text { gastronomía. }\end{array}$ & & $\mathrm{X}$ & & & & & \\
\hline $\begin{array}{l}\text { La comunidad respalda al CTC de forma silente, debido a la descoordinación y poca } \\
\text { gestión realizada, ya que, no se sienten representados por quienes lideran la actividad } \\
\text { turística. }\end{array}$ & & & $\mathrm{X}$ & & & & \\
\hline $\begin{array}{l}\text { La comunidad expresa su descontento por la falta de planificación y gestión por los } \\
\text { representantes del CTC, tal es el sentir que prefiere trabajar en sus propios negocios. }\end{array}$ & & & & $\mathrm{X}$ & & & \\
\hline La poca afluencia de turistas desmotivan a la población, no obstante apoyan al CTC. & & & & & $\mathrm{X}$ & & \\
\hline $\begin{array}{l}\text { La comunidad apoya al CTC, ya que combinan las actividades cotidianas con el } \\
\text { agroturismo. }\end{array}$ & & & & & & $\mathrm{X}$ & \\
\hline $\begin{array}{l}\text { La población aporta con ideas al desarrollo del turismo en el CTC para impulsar sus } \\
\text { negocios a pesar del difícil acceso al sector que es la principal debilidad. }\end{array}$ & & & & & & & $\mathrm{X}$ \\
\hline
\end{tabular}

Fuente: Base de datos encuesta octubre 2019-febrero 2020.

En sí, las comunidades ratifican que los CTC coadyuvan al desarrollo y dinamizan la economía local y el buen vivir, siempre y cuando los beneficios generados sean reinvertidos en casa para el cuidado de las costumbres y tradiciones, lo cual en algunos casos se dilata por el desinterés, la mala planificación y gestión de los líderes que encabezan el proyecto comunitario, lo que genera malestar en las comunidades, haciendo que la población se dedique a otras actividades como la agricultura y ganadería.

En cuanto al análisis de las entrevistas realizadas a los diferentes actores de cada una de las direcciones de turismo de las provincias que conforman la zona tres del Ecuador respecto a la situación económica, política e institucional de los CTC para el fomento y buen vivir de las comunidades a través del turismo comunitario, se obtuvieron los siguientes resultados. 
Tabla 8. Dimensión económica, política e institucional de los CTC de la zona tres del Ecuador.

\begin{tabular}{|c|c|}
\hline CTC & Análisis de resultados \\
\hline $\begin{array}{c}\text { Lago Verde } \\
\text { Quilotoa }\end{array}$ & $\begin{array}{l}\text { El ing. Marcelo Parra representante de la dirección de turismo de Cotopaxi menciona: } \\
\checkmark \quad \text { El CTC aporta muy poco al desarrollo local de la comunidad, ya que el proyecto no ha sido aprovechado de } \\
\text { manera conjunta sino individual, y esto no ha beneficiado en sí a toda la comunidad. } \\
\checkmark \quad \text { El turismo aporta al PIB, no obstante, la visita a las áreas protegidas en la provincia ha sido más significativa. } \\
\checkmark \quad \text { El MINTUR y el Consejo Provincial han habilitado el mirador de la laguna Quilotoa para dinamizar la } \\
\checkmark \\
\text { economía local. } \\
\text { El turismo comunitario se desarrolla con el apoyo de las instituciones públicas y con el trabajo equitativo de } \\
\text { la comunidad para el buen vivir de todos. } \\
\quad \text { El turismo de la provincia se fortalece a través de las ferias de promoción turística e implementación de } \\
\checkmark \quad \text { señalética turística. }\end{array}$ \\
\hline $\begin{array}{l}\text { Palacio Real } \\
\text { La Moya } \\
\text { Tolte-Pistishi } \\
\text { Quilla Pacari }\end{array}$ & 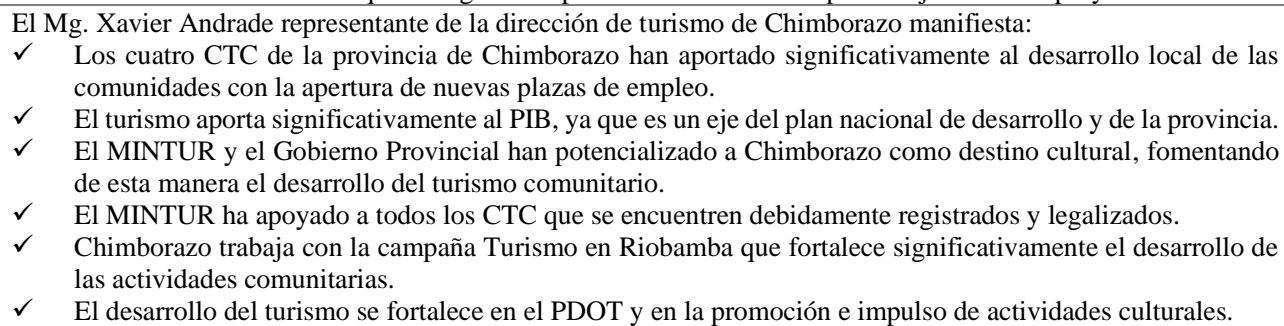 \\
\hline Pondoa & $\begin{array}{l}\text { El Lic. Esteban Aguilar representante de la dirección de turismo de Baños de la provincia de Tungurahua menciona: } \\
\checkmark \quad \text { El CTC de Pondoa ha incrementado su infraestructura turística, generando empleo y dinamizando la economía } \\
\checkmark \quad \text { local y el buen vivir. } \\
\checkmark \quad \text { Es mínimo el aporte del turismo al PIB, no obstante, es una oportunidad de vida para las comunidades. } \\
\text { El Honorable Consejo Provincial de Tungurahua y el GAD de Baños han aportado al fortalecimiento del } \\
\text { turismo comunitario, invirtiendo en material publicitario y capacitaciones. } \\
\text { El MINTUR establece políticas y lineamientos como ente regulador para el desarrollo del turismo } \\
\text { comunitario, que en ocasiones entorpecen la actividad turística. } \\
\checkmark \quad \begin{array}{l}\text { Para promover el desarrollo del turismo comunitario a la par se está trabajando con el proyecto Pueblos } \\
\text { Mágicos y Geoparque Volcán Tungurahua. }\end{array} \\
\checkmark \quad \text { Para fortalecer el turismo de la provincia se está trabajando en la reestructuración del POA. }\end{array}$ \\
\hline Sharamentsa & $\begin{array}{l}\text { El Mg. Juan Olivo representante de la dirección de turismo de Pastaza manifiesta: } \\
\checkmark \quad \text { El turismo comunitario es un generador de resultados y una herramienta de desarrollo local siempre y cuando } \\
\text { se trabaje organizados y con un mismo horizonte en común. } \\
\checkmark \quad \text { El turismo rural aporta el } 2 \% \text { al PIB, donde la práctica de turismo comunitario es evidente en la provincia de } \\
\checkmark \quad \text { Pastaza a través de CTC y emprendimientos turísticos comunitarios (ETC). } \\
\text { El GAD municipal aporta con capacitaciones, el Consejo Provincial con vialidad y acceso a los atractivos y } \\
\checkmark \quad \text { el MINTUR es el ente que controla la actividad turística. } \\
\checkmark \quad \text { Son varios los requerimientos que exige el MINTUR para registrar a los centros de turismo comunitario. } \\
\text { Para fortalecer el turismo comunitario y el territorio, hay cinco proyectos centrado en rutas turísticas: de } \\
\text { aventura (turismo de aventura), de los ancestros (cultural), del sabor (gastronomía), de las plumas (aviturismo) } \\
\checkmark \quad \text { y de las orquídeas (investigación). } \\
\text { La planificación es un instrumento que ha aportado al desarrollo local. }\end{array}$ \\
\hline
\end{tabular}

Fuente: Base de datos de la entrevista de febrero 2020.

Como se evidencia en la tabla anterior, el turismo comunitario aporta significativamente al avance de las comunidades del objeto de estudio, ya que en parte ha generado fuentes de empleo a la población, tal es el caso de los CTC de la provincia de Chimborazo, Tungurahua y Pastaza donde además el turismo comunitario es una herramienta para la conservación de las costumbres y tradiciones, un medio de desarrollo económico para las comunidades y generador de resultados positivos tras plantearse objetivos y metas claras en beneficio de la población local y el buen vivir.

Por otra parte, en Lago Verde-Quilotoa de la provincia de Cotopaxi el turismo comunitario se ha individualizado, a tal punto de que los beneficios no se generan para la comunidad sino 
a cada familia siendo este un problema institucional que el MINTUR debe solucionar para la regulación efectiva de la actividad turística en las comunidades.

Es importante indicar que en la investigación, el turismo en comunidades indígenas, se ha desarrollado más en entornos familiares, generando de esta manera más emprendimientos turísticos comunitarios (ETC) que centros de turismo comunitario (CTC), debido a las facilidades de constitución que exige para ser considerado un emprendimiento, a diferencia del Centro de Turismo Comunitario que está bajo principios de responsabilidad compartida y distribución equitativa de sus beneficios con la comunidad, lo cual no sucede con los ETC cuyos beneficios son familiares por lo que se le considera como una microempresa turística.

Un elemento importante a considerar es el proyecto de Pueblos Mágicos que se está trabajando con el fin de promover el desarrollo turístico de la zona tres a más del proyecto Geoparque Volcán Tungurahua que en sí guardan relación en pro de potencializar el turismo rural en las comunidades para su fortalecimiento y buen vivir.

\section{Conclusiones.}

- La práctica del agroturismo en la zona tres del Ecuador es un factor muy importante dentro del turismo comunitario como un medio que fortalece la oferta comunitaria, así como la oferta de alojamiento en cabañas que determina a la mayoría de los centros de turismo comunitario.

- La demanda actual de los CTC de Tolte, Palacio Real y Sharamentsa en un 90\% está representado en turistas extranjeros como norteamericanos, canadienses y alemanes, mientras que los turistas nacionales en su mayoría están en Lago Verde, Quilla Pacari y Pondoa

- El turismo comunitario es un potencial, una línea de acción que incide en la sociedad, en la revalorización de las costumbres y tradiciones, el cuidado de la naturaleza parte esencial del ambiente y la gestión comunitaria que fortalece el buen vivir de las comunidades de las zona tres del Ecuador que ven en el turismo rural una alternativa de desarrollo local.

- El turismo comunitario en la zona tres del Ecuador se perfila como una oportunidad de vida para las comunidades que a través del fortalecimiento y una efectiva gestión inciden en el desarrollo local tras generar fuentes de trabajo, creando valor en cada una de las actividades que nace de la población con el fin de superar los problemas económicos que se presentan en el diario vivir.

- El turismo comunitario trabajada desde la política pública, es una herramienta de desarrollo local para las comunidades que incide en la calidad de vida y el buen vivir de la población que conjuntamente con el apoyo de las instituciones públicas y privadas 
dinamizan la economía del sector, pues a más de ser una actividad dinamizadora, da protagonismo a la mujer y a los jóvenes de cada uno de los pueblos de la zona tres del Ecuador.

\section{Referencias bibliográficas.}

Acerenza, M. (2013). Desarrollo sostenible y gestión del turismo. México: Trillas. Alburquerque, F. (2004). Desarrollo económico local y descentralización en América Latina. Revista de la CEPAL No.82, 157-171. http://hdl.handle.net/11362/10946

Arias, R., Carpio, T., Herrera, A., \& González, R. (2016). Diversified crop indigenous system and local development in Ecuadorian Amazonia. Cultivos Tropicales, 37(2), 7-14. https://doi.org/10.13140/RG.2.1.1878.1688

Arocena, J. (2001). “Capítulo IX: Una investigación de procesos de desarrollo local”. Cap. In El desarrollo local: un desafío contemporáneo. p. 201-229. Montevideo: Ediciones Santillana. Universidad Católica de Urugual.

Asamblea Nacional del Ecuador. Constitución de la República del Ecuador. (2008). Montecristi, Ecuador.

Ayala Mora, E. (2008). Resumen de historia del Ecuador. Ecuador: Corporación Editora Nacional.

Cabanilla Vásconez, E. \& Garrido Cornejo, C. (2018). El Turismo comunitario en el Ecuador: Evolución, problemática y desafíos. Ecuador: UIDE.

Cabanilla, E. (2018). Turismo comunitario en América Latina, un concepto en construcción. Siembra. Revista de investigación científica, 5(1), 121-131.

Cárdenas, N. (2002). El desarrollo local su conceptualización y procesos. Provincia, (8),5376. Consultado 26 de marzo, 2020, Obtenido de: https://www.redalyc.org/articulo.oa?id=555/55500804

Chávez, W. (2008). Políticas públicas para un desarrollo endogeno sustentable en paises en desarrollo. Revista OIDLES: Observatorio Iberoamericano del Desarrollo Local y la Economía Social, (3) Universidad de Málaga.

Cruz, D., Ojalvo Mitrany, V., \& Velasteguí López, E. (2019). Desarrollo local: conceptualizaciones, principales características y dimensiones. Ciencia Digital, 9(2), 319-335. https://doi.org/10.33262/cienciadigital.v9i2.353

Díaz, J. (2018). Principios Básicos del Desarrollo Local. 11-31. Consultado 20 de marzo, 2020, Obtenido de: https://www.faeditorial.es/capitulos/agente-de-desarrollo-yempleo-local.pdf

Estrada Ayala, G. P. (2015). El turismo comunitario como estrategia de desarrollo local y mejora en las condiciones de vida: Estudio de caso de la comunidad de Nízag. Ecuador: Facultad Lationamericana de Ciencias Sociales.

Fundación CODESPA. (2011). Modelo de gestión del turismo rural comunitario de CODESPA: Una experiencia regional Andina. Consultado 26 de marzo, 2020, Obtenido de: 
https://www.google.com/url?sa=t \&rct=j\&q=\&esrc=s\&source=web\&cd=2\&ved=2a hUKEwi8z9aD0uHoAhWxmuAKHQkaA_EQFjABegQIBRAB\&url=http\%3A\%2F $\% 2 \mathrm{Fwww}$.bibliotecavirtualrs.com\%2Fwpcontent $\% 2$ Fuploads $\% 2 \mathrm{~F} 2013 \% 2 \mathrm{~F} 02 \% 2 \mathrm{Fmodelo}$-gestion-turismo-ruralcomunitario-codespa.pdf\&usg=AOvVaw0RqdYEaz8NaYHfRZeMc2Vb

Guzmán, T., \& Sánchez, S. (2009). Turismo comunitario y generación de riqueza en países en vías de desarrollo. Un estudio de caso en El Salvador. Revista de Estudios Corporativos (Revesco). (99), 85-103.

Hernández, R., Fernández, C., \& Baptista, P. (2014). Metodología de la investigación. México: McGraw-Hill.

Maldonado, C. (2005). Pautas metodológicas para el análisis de experiencias de turismo comunitario. In Serie Red de Turismo Sostenible Comunitario para América Latina (REDTURS) (Vol. 73).

Ministerio de Turismo del Ecuador (MINTUR). Instructivo para registro de centros turisticos comunitarios. (2009). Quito, Ecuador.

Misniterio de Turismo del Ecuador (MINTUR). Reglamento para los centros turisticos comunitarios. (2010). Quito, Ecuador.

Monge Rodríguez, Y., \& Macías Chávez, A. (2016). El desarrollo local. Enfoques para su conceptualización. Olimpia: Publicación Científica de La Facultad de Cultura Física de La Universidad de Granma, 13(39), 226-238.

Morales Pérez, M. (2006). El desarrollo local sostenible. Economía y Desarrollo, 140(2),6071. Consultado 26 de marzo, 2020, Obtenido de: https://www.redalyc.org/articulo.oa?id=4255/425541310004

Organización Mundial del Turismo y Organización de los Estados Americanos (2018), El turismo y los Objetivos de Desarrollo Sostenible - Buenas prácticas en las Américas, OMT, Madrid. DOI: https://doi.org/10.18111/9789284419937.

Organización Mundial del Turismo. (2016). El sector turístico y los objetivos de desarrollo sostenible. Turismo responsable, un compromiso de todos, OMT, Red Española del Pacto Mundial de Naciones Unidas, Madrid. Editorial Edamel.

Ortiz, D., \& Arévalo, N. (2014). El Desarrollo Sostenible y Desarrollo Sustentable: Concepto, Uso y Pertinencia. Universidad La Gran Colombia (UGC), 1-15. https://doi.org/10.1042/BJ20100609

Palomino Villavicencio, B., Gasca Zamora, J., \& López Pardo, G. (2016). El turismo comunitario en México: perspectiva desde las instituciones y la gobernanza en territorios indígenas. El Periplo Sustentable, (30), 06-37.

PROCASUR. (2011). Manejo del Turismo Comunitario-Ecuador. Consultado 17 de marzo, 2020, Obtenido de: http://procasur.org/americalatina/images/Generingreso/1. Manejo del Turismo Comunitario-Ecuador (Documento Tem\%23U00e1tico) 2011 11 20.pdf 
Programa de las Naciones Unidas para el Desarrollo. (PNUD), (2018). Índices e indicadores de desarrollo humano: Actualización estadística de 2018. Consultado 25 de marzo, 2020 ,

http://hdr.undp.org/sites/default/files/2018_human_development_statistical_update_ es.pdf

Reyes, M., Ortega, Á., \& Machado, E. (2017). Modelo para la gestión integrada del turismo comunitario en Ecuador, caso de estudio Pastaza. REVESCO Revista de Estudios Cooperativos, 123, 250-275.

Rodas, M., Ullauri Donoso, N., \& Sanmartín, I. (2015). El Turismo Comunitario en el Ecuador: Una revisión de la literatura. Turismo, Desarrollo y Buen Vivir. Revista de Investigación de la Ciencia Turística - RICIT, (9), 60-77.

Román, F., \& Ciccolella, M. (2009). Turismo rural en la Argentina: concepto, situación y perspectivas. Argentina: IICA.

Roux, F. (2013). Turismo comunitario ecuatoriano, conservacion ambiental y defensa de los territorios. Federación Plurinacional de Turismo Comunitario del Ecuador (FEPTCE). Quito-Ecuador. Consultado 10 de marzo, 2020, Obtenido de: https://www.academia.edu/7801608/Turismo_comunitario_ecuatoriano_conservaci on_ambiental_y_defensa_de_los_territorios._FEPTCE._Estudio_completo._2013

Ruiz, E., \& Solis, D. (2007). Turismo comunitario en Ecuador: desarrollo y sostenibilidad social. Ecuador: Abya-Yala.

Sancho, A. (2008). Introducción al Turismo. Consultado 10 de marzo, 2020, Obtenido de: http://www.utntyh.com/wp-content/uploads/2011/09/INTRODUCCION-ALTURISMO-OMT.pdf

SENPLADES. (2009). Plan Nacional de Desarrollo. Plan Nacional para el Buen Vivir 20092013. Quito-Ecuador: Senplades.

SENPLADES. (2013). Plan Nacional de Desarrollo. Plan Nacional para el Buen Vivir 20132017. Quito-Ecuador: Senplades.

SENPLADES. (2017). Plan Nacional de Desarrollo 2017-2021. Toda una Vida. QuitoEcuador: Senplades.

Washburn Herrera, C., Vergara Díaz, N., \& Flores Poveda, J. (2016). Reflexiones sobre experiencias de desarrollo local en Europa, América Latina y Ecuador. Revista DELOS: Desarrollo Local Sostenible, 9(27), 3.

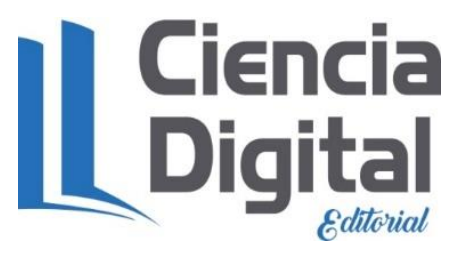




\section{PARA CITAR EL ARTÍCULO INDEXADO.}

Palomino Siza, L. B., Cabanilla Vásconez, E. A., \& García Quintana, Y. (2020). Turismo comunitario en la zona tres del Ecuador: Un análisis de la incidencia en el desarrollo local . Explorador Digital, 4(4), 50-69. https://doi.org/10.33262/exploradordigital.v4i4.1414

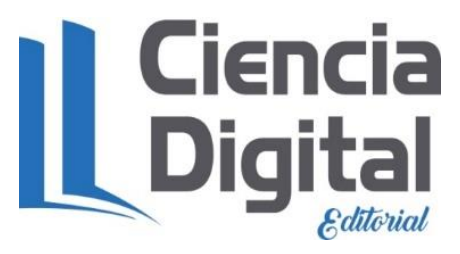

El artículo que se publica es de exclusiva responsabilidad de los autores y no necesariamente reflejan el pensamiento de la Revista Explorador Digital.

El artículo queda en propiedad de la revista y, por tanto, su publicación parcial y/o total en otro medio tiene que ser autorizado por el director de la Revista Explorador Digital.
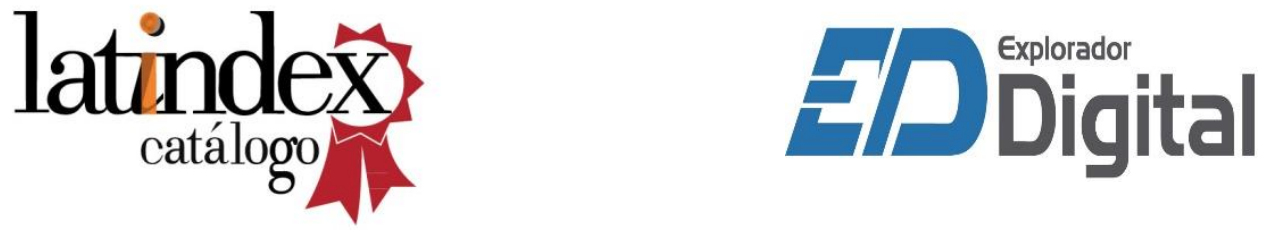